\title{
A Thermodynamics Study on the Tetrahydrofuran Effect in Exfoliated Graphite Nanoplatelets and Activated Carbon Mixtures at Temperatures between 293.15 and $308.15 \mathrm{~K}$
}

\author{
Florinela Sirbu $\mathbb{D}^{1}{ }^{1}$ Alina Catrinel Ion, ${ }^{2}$ Luiza Capra, ${ }^{3}$ and Ion Ion $^{2}$ \\ ${ }^{1}$ Department of Chemical Thermodynamics, "Ilie Murgulescu" Institute of Physical Chemistry of Romanian Academy, \\ 202 Splaiul Independentei St., 060021 Bucharest, Romania \\ ${ }^{2}$ Department of Analytical Chemistry and Instrumental Analysis, Faculty of Applied Chemistry and Material Science, \\ "Politehnica" University of Bucharest, 1 Polizu St., 011061 Bucharest, Romania \\ ${ }^{3}$ Department of Analysis, Tests, and Testings, National Research \& Development Institute for Chemistry and Petrochemistry \\ ICECHIM, 202 Splaiul Independentei St., 060021 Bucharest, Romania
}

Correspondence should be addressed to Florinela Sirbu; sflorinela@yahoo.com

Received 30 November 2017; Accepted 5 February 2018; Published 29 March 2018

Academic Editor: Peter Majewski

Copyright (c) 2018 Florinela Sirbu et al. This is an open access article distributed under the Creative Commons Attribution License, which permits unrestricted use, distribution, and reproduction in any medium, provided the original work is properly cited.

A thermodynamics study on exfoliated graphite nanoplatelets dispersed in tetrahydrofuran in comparison with activated carbon dispersed in same solvent was realised. The refractive index, speed of sound, and density of diluted mixed binary solutions of exfoliated graphite nanoplatelets and activated carbon in tetrahydrofuran were measured between 0 and $100 \mathrm{~kg} \cdot \mathrm{m}^{-3}$ with composition step of $20 \mathrm{~kg} \cdot \mathrm{m}^{-3}$ and at temperatures from 293.15 to $308.15 \mathrm{~K}$ and at normal pressure. The isentropic compressibility, acoustic impedance, specific refraction, relaxation strength, and space-filling factor have been evaluated for six concentrations, at four different temperatures for each system. The identified possible molecular interactions between the edges and the surface of exfoliated graphite nanoplatelets and tetrahydrofuran molecules, which include modifications in the structure of exfoliated nanostructured materials in tetrahydrofuran solvent and the influence of the temperature, and of the solute concentration have been calculated based on the obtained experimental values.

\section{Introduction}

Investigations of acoustical and optical parameters of binary solutions of tetrahydrofuran (THF) with exfoliated graphite nanoplatelets $(\mathrm{xGnP})$ and activated carbon $(\mathrm{AC})$ were realised based on their physicochemical behaviour. The physicochemical parameters strongly influence the dispersion of $\mathrm{xGnP}$ carbon-based nanomaterials compared with the dispersions of AC in THF, offering new information about the structure and interactions of carbon-based nanostructures in organic solvents [1]. Graphite-based nanomaterials can be classified based on the thickness, the number, and the disposal of the exfoliated layers [2]. Graphite nanoplatelets with dimensions of 3 to $30 \mathrm{~nm}$ thick and 10-100 graphene layers, known as exfoliated graphite nanoplatelets, present similar electrochemical behaviour, irrespective of the number of layers [3]. Even though the number of articles about $\mathrm{xGnP}$ greatly increased $[4,5]$, data on their thermodynamic properties, thermophysical behaviour description, and molecular modelling are still missing. The characterization of graphene dispersed in dimethylsulfoxide (DMSO) and dimethylformamide (DMF) polar solvents was published by Shih et al. [6]. It has been noted that DMSO solvent can break the ties in polymerised compounds of oxygenated chemical structures [7]. In the last years, the dispersion of $\mathrm{xGnP}$ in DMF and water was also studied [8].

The aim of the present study was to provide new experimental values on thermophysical properties such as refractive indices, speeds of sound, and densities in the 
TABLE 1: Specifications of exfoliated graphite nanoplatelets, activated carbon, and THF chemicals used in mixtures.

\begin{tabular}{lccccc}
\hline $\begin{array}{l}\text { Chemical } \\
\text { name }\end{array}$ & Source & $\begin{array}{c}\text { Initial mass fraction } \\
\text { purity }\end{array}$ & $\begin{array}{c}\text { Purification } \\
\text { method }\end{array}$ & $\begin{array}{c}\text { Final mass fraction } \\
\text { purity }\end{array}$ & $\begin{array}{c}\text { Analysis } \\
\text { method }\end{array}$ \\
\hline AC & $\begin{array}{c}\text { Sigma-Aldrich } \\
\text { XGnP }\end{array}$ & XG Sciences, (Lansing, MI, & $>0.99$ carbon & None & - \\
THF & USA) & $>0.95$ carbon & None & - & - \\
\hline
\end{tabular}

AC: activated carbon; xGnP: exfoliated graphite nanoplatelets; THF: tetrahydrofuran.

TABLE 2: Comparison of experimental densities $(\rho)$, speeds of sound $(c)$, and refractive indices $\left(n_{\mathrm{D}}\right)$ of pure tetrahydrofuran with literature values at various temperatures.

\begin{tabular}{|c|c|c|c|}
\hline $\mathrm{T}(\mathrm{K})$ & Present work & & Reference \\
\hline \multicolumn{4}{|c|}{$\rho\left(\mathrm{g} \cdot \mathrm{cm}^{-3}\right)$} \\
\hline \multirow[t]{2}{*}{293.15} & 0.88762 & 0.88750 & {$[23]$} \\
\hline & & 0.88947 & [25] \\
\hline \multirow[t]{4}{*}{298.15} & 0.88216 & 0.88205 & [27] \\
\hline & & 0.88504 & [25] \\
\hline & & 0.88206 & {$[30]$} \\
\hline & & 0.88207 & [31] \\
\hline \multirow[t]{3}{*}{303.15} & 0.87664 & 0.87710 & [27] \\
\hline & & 0.88076 & [25] \\
\hline & 0.87114 & 0.87214 & [27] \\
\hline \multirow[t]{3}{*}{308.15} & & 0.87663 & [25] \\
\hline & & 0.87710 & [35] \\
\hline & \multicolumn{2}{|c|}{$c\left(\mathrm{~m} \cdot \mathrm{s}^{-1}\right)$} & \\
\hline 293.15 & 1303.65 & 1302.00 & {$[24]$} \\
\hline 298.15 & 1279.38 & 1277.60 & {$[28]$} \\
\hline \multirow[t]{2}{*}{303.15} & 1255.24 & 1258.00 & [32] \\
\hline & & 1254.00 & [33] \\
\hline \multirow[t]{2}{*}{308.15} & 1231.10 & 1231.70 & {$[35]$} \\
\hline & & & \\
\hline \multirow[t]{2}{*}{293.15} & 1.40731 & 1.4064 & {$[23]$} \\
\hline & & 1.4071 & {$[26]$} \\
\hline 298.15 & 1.40464 & 1.4049 & [29] \\
\hline \multirow{2}{*}{303.15} & 1.40198 & 1.4026 & [29] \\
\hline & & 1.4030 & [34] \\
\hline 308.15 & 1.39932 & 1.4008 & [29] \\
\hline
\end{tabular}

$\mathrm{THF}+\mathrm{xGnP}$ or THF $+\mathrm{AC}$ binary systems for which experimental data are not available. The binary mixtures were measured at atmospheric pressure, using various compositions of solutes between 0 and $100 \mathrm{~kg} \cdot \mathrm{m}^{-3}$ with increments of $20 \mathrm{~kg} \cdot \mathrm{m}^{-3}$ and at temperatures of 293.15, 298.15, 303.15 , and $308.15 \mathrm{~K}$. The effect of the variation of these parameters on the concentrations in the studied mixed solutions was evaluated. Based on the understanding of the molecular interactions, several applications could be envisaged, such as sensors with composite nanomaterials [2]. These infield detection systems are used for monitoring the environmental stress. The sorbents based on composite nanomaterials are also used for the removal of contaminants, or to allow the administration of drugs [9] from mixed solutions [10]. Among the applications of nanotechnologies, new types of sorbents based on carbon nanomaterials are studied and further applied for the removal of environmental contaminants based on their interactions at the molecular level [11-13].

\section{Experimental Section}

2.1. Materials and Methods. Exfoliated graphite nanoplatelets were purchased from XG Sciences (Lansing, MI, USA) and are characterized by mass fraction of $>0.95$ carbon, thickness of approximately $15 \mathrm{~nm}$, diameter of $25 \mu \mathrm{m}$, and surface area of $50-80 \mathrm{~m}^{2} \cdot \mathrm{g}^{-1}$. THF was supplied from Merck and activated carbon (mass fraction $>0.99$ ) from Sigma-Aldrich. These chemical compounds have been used without further purification, except drying over $\mathrm{P}_{2} \mathrm{O}_{5}$ for $72 \mathrm{~h}$, for those with a mass fraction purity of $>0.95$. In Table 1, the specifications for the chemical compounds used in the working sample preparation are presented.

Working solutions of $\mathrm{AC}+\mathrm{THF}$ and $\mathrm{xGnP}+\mathrm{THF}$ with different concentrations have been prepared at $298.15 \mathrm{~K}$ using THF of analytical purity (p.a.). The binary mixed solutions have been freshly prepared and kept in airtight bottles by mixing known compositions of stock and pure THF solvent. All precautions have been taken to minimise 
TABLE 3: Experimental values of the densities $\rho$, speeds of sound $c$, and refractive indices $n_{\mathrm{D}}$ at various temperatures $T$ and specific concentrations $C$ of $\mathrm{AC}$ for the system $\mathrm{AC}+\mathrm{THF}{ }^{\mathrm{a}}$

\begin{tabular}{|c|c|c|c|c|c|c|}
\hline$T(\mathrm{~K})$ & $\rho\left(\mathrm{kg} \cdot \mathrm{m}^{-3}\right)$ & $c\left(\mathrm{~m} \cdot \mathrm{s}^{-1}\right)$ & $n_{\mathrm{D}}$ & $\rho\left(\mathrm{kg} \cdot \mathrm{m}^{-3}\right)$ & $c\left(\mathrm{~m} \cdot \mathrm{s}^{-1}\right)$ & $n_{\mathrm{D}}$ \\
\hline & & $C\left(\mathrm{~kg} \cdot \mathrm{m}^{-3}\right)=0$ & & & $C\left(\mathrm{~kg} \cdot \mathrm{m}^{-3}\right)=20$ & \\
\hline 293.15 & 887.62 & 1303.65 & 1.40731 & 887.66 & 1303.61 & 1.40731 \\
\hline 298.15 & 882.16 & 1279.38 & 1.40464 & 882.21 & 1279.46 & 1.40465 \\
\hline 303.15 & 876.64 & 1255.24 & 1.40198 & 876.68 & 1255.31 & 1.40200 \\
\hline 308.15 & 871.14 & $\begin{array}{c}1231.10 \\
C\left(\mathrm{~kg} \cdot \mathrm{m}^{-3}\right)=40\end{array}$ & 1.39932 & 871.18 & $\begin{array}{c}1231.19 \\
C\left(\mathrm{~kg} \cdot \mathrm{m}^{-3}\right)=60\end{array}$ & 1.39935 \\
\hline 293.15 & 887.72 & 1303.59 & 1.40731 & 887.76 & 1303.62 & 1.40732 \\
\hline 298.15 & 882.23 & 1279.52 & 1.40466 & 882.29 & 1279.58 & 1.40467 \\
\hline 303.15 & 876.74 & 1255.37 & 1.40201 & 876.80 & 1255.41 & 1.40202 \\
\hline 308.15 & 871.21 & $\begin{array}{c}1231.26 \\
C\left(\mathrm{~kg} \cdot \mathrm{m}^{-3}\right)=80\end{array}$ & 1.39936 & 871.27 & $\begin{array}{c}1231.37 \\
C\left(\mathrm{~kg} \cdot \mathrm{m}^{-3}\right)=100\end{array}$ & 1.39938 \\
\hline 293.15 & 887.80 & 1303.72 & 1.40733 & 887.87 & 1303.72 & 1.40733 \\
\hline 298.15 & 882.34 & 1279.64 & 1.40468 & 882.41 & 1279.64 & 1.40468 \\
\hline 303.15 & 876.85 & 1255.49 & 1.40203 & 876.91 & 1255.49 & 1.40203 \\
\hline 308.15 & 871.32 & 1231.46 & 1.39938 & 871.39 & 1231.46 & 1.39938 \\
\hline
\end{tabular}

${ }^{\mathrm{a}} C\left(\mathrm{~kg} \cdot \mathrm{m}^{-3}\right)$ is the specific concentration of AC in the THF solvent. Standard uncertainties $(u)$ are $u(T)=0.001 \mathrm{~K}$ for $\rho$ and $c$ and $u(T)=0.01 \mathrm{~K}$ for $n_{\mathrm{D}}$, and the combined expanded uncertainties $\left(U_{\mathrm{c}}\right)$ are $U_{\mathrm{c}}(\rho)=0.01 \mathrm{~kg} \cdot \mathrm{m}^{-3}, U_{\mathrm{c}}(c)=0.05 \mathrm{~m} \cdot \mathrm{s}^{-1}$ (level of confidence $\left.=0.95, k=2\right)$, and $U_{\mathrm{c}}\left(n_{\mathrm{D}}\right)=0.00001$.

TABLE 4: Experimental values of the densities $\rho$, speeds of sound $c$, and refractive indices $n_{\mathrm{D}}$ at various temperatures $T$ and specific concentrations $C$ of $\mathrm{xGnP}$ for the system $\mathrm{xGnP}+\mathrm{THF}^{\mathrm{a}}$

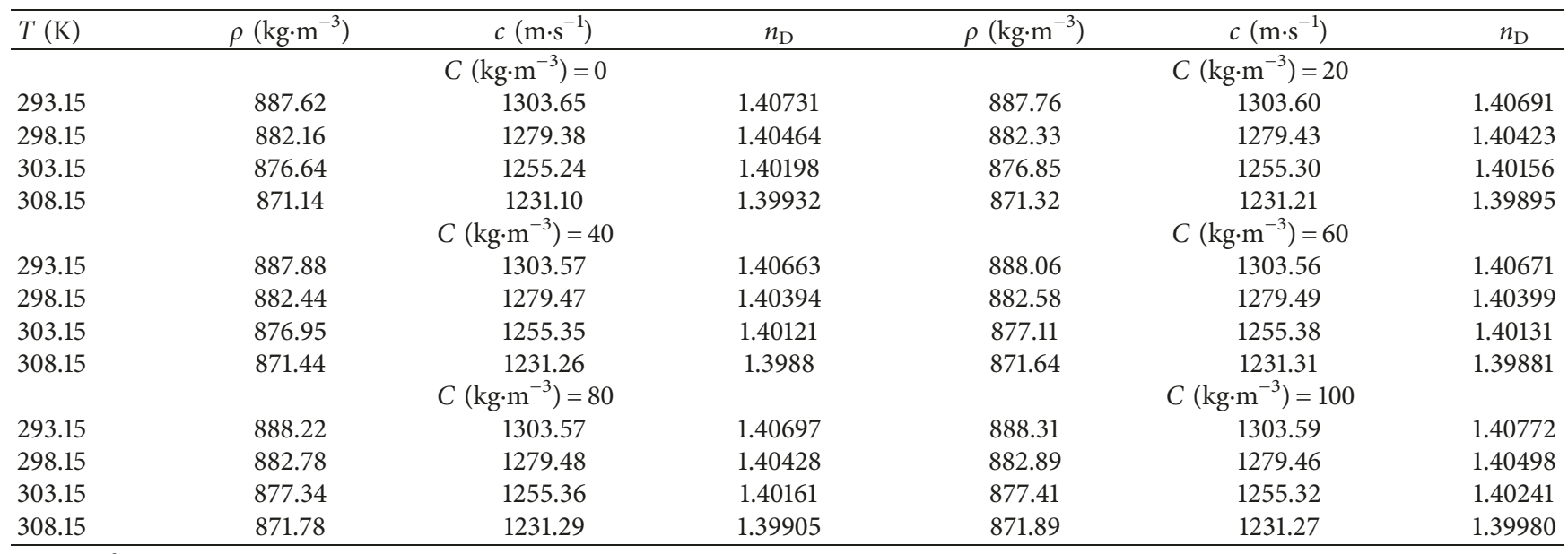

${ }^{\mathrm{a}} \mathrm{C}\left(\mathrm{kg} \cdot \mathrm{m}^{-3}\right)$ is the specific concentration of $\mathrm{xGnP}$ in THF solvent. Standard uncertainties $(u)$ are $u(T)=0.001 \mathrm{~K}$ for $\rho$ and $c$ and $u(T)=0.01 \mathrm{~K}$ for $n_{\mathrm{D}}$, and the combined expanded uncertainties $\left(U_{\mathrm{c}}\right)$ are $U_{\mathrm{c}}(\rho)=0.01 \mathrm{~kg} \cdot \mathrm{m}^{-3}, U_{\mathrm{c}}(c)=0.1 \mathrm{~m} \cdot \mathrm{s}^{-1}$ (level of confidence $=0.95, k=2$ ), and $U_{\mathrm{c}}\left(n_{\mathrm{D}}\right)=0.00001$.

the errors produced by the evaporation of solutions. Specific concentration was expressed in $\mathrm{kg} \cdot \mathrm{m}^{-3}$ as measured unit. The initial compositions of the stock mixtures were prepared with an accuracy of $\pm 0.2 \mathrm{~kg} \cdot \mathrm{m}^{-3}$. More details about the refractive indices, speeds of sound, and densities experimental measurements and procedures can be found in previous papers $[8,14,15]$.

The refractive index of the samples was measured with an Anton Paar GmbH Abbe automatic refractometer at a controlled temperature within $\pm 0.01 \mathrm{~K}$ and a precision of \pm 0.000001 . The calibration of the refractometer has been done by measuring the refractive index of deionised twice distilled pure water. The speeds of sound and densities of mixed solutions have been measured with Anton Paar DSA 5000 digital (Austria) equipment under atmospheric pressure. The precision of the density is of $\pm 0.001 \mathrm{~kg} \cdot \mathrm{m}^{-3}$.
The speed of sound has been measured at a reduced wavelength and a low frequency of approximately $3 \mathrm{MHz}[16,17]$, and the precision is $\pm 0.01 \mathrm{~m} \cdot \mathrm{s}^{-1}$. The temperature was controlled by several Peltier units with a precision of $\pm 0.001 \mathrm{~K}$ for obtaining the speed of sound and density experimental data.

The densitometer instrument was internally calibrated with air and doubly distilled deionised pure water by determining the speed of sound and density at normal pressure, according to the recommendations of the manufacturer. The density, speed of sound, and refractive index values of water at $298.15 \mathrm{~K}$ were measured as $0.99706 \mathrm{~g} \cdot \mathrm{cm}^{-3}, 1497.1 \mathrm{~m} \cdot \mathrm{s}^{-1}$, and 1.33248 , similar to the values described in the literature [18-21], with a reproducibility of $\pm 0.000005 \mathrm{~g} \cdot \mathrm{cm}^{-3}, \pm 0.04 \mathrm{~m} \cdot \mathrm{s}^{-1}$, and \pm 0.000005 units, respectively. Uncertainties associated with the experimentally measured data for refractive index, 


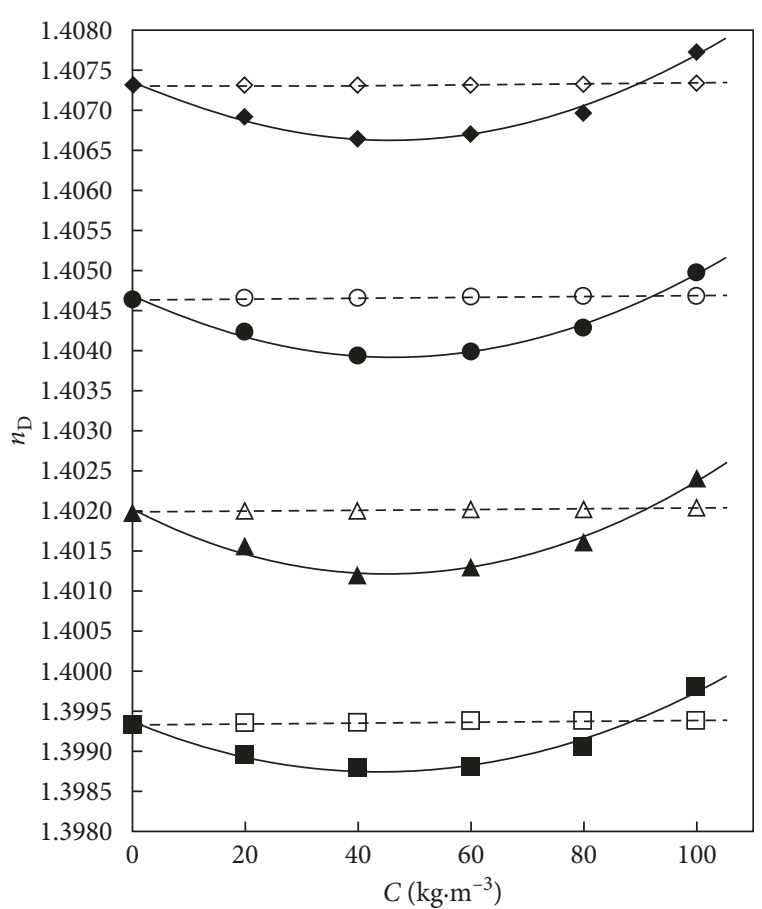

FIGURE 1: Comparative representation of the refractive indices of binary $\mathrm{xGnP}+\mathrm{THF}$ and $\mathrm{AC}+\mathrm{THF}$ systems versus concentration of the solute at various temperatures, $T(\mathrm{~K})$ : filled diamond, 293.15; filled circle, 298.15; filled triangle, 303.15; filled square, 308.15; for xGnP: open diamond, 293.15; open circle, 298.15; open triangle, 303.15; open square, 308.15; for AC: solid line, dashed line; polynomial correlated values.

speed of sound, and density were presented under each data table, according to the guide for evaluation of measurement data [22].

2.2. Theory and Calculation. The acoustical and optical thermodynamic properties such as isentropic compressibility $\left(k_{\mathrm{S}}\right)$, impedance $(Z)$, space-filling factor $(S)$, specific refraction $\left(r_{\mathrm{D}}\right)$, and relaxation strength $(r)$ at various temperatures and atmospheric pressure were estimated from experimental results of density, speed of sound, and refractive index. The calculation relations for the derived thermophysical properties have been described elsewhere $[8,14,15]$.

\section{Results and Discussion}

Experimental data on densities $(\rho)$, speeds of sound $(c)$, and refractive indices $\left(n_{\mathrm{D}}\right)$ as a function of specific concentration of $\mathrm{xGnP}$ or $\mathrm{AC}$ in THF solvent at a pressure of $0.1 \mathrm{MPa}$ are reported. The experimental values of these properties at atmospheric pressure for the pure THF solvent in comparison with literature values [23-35] at different temperatures from 293.15 up to $308.15 \mathrm{~K}$ are presented in Table 2.

The carbon-based nanoplatelets and activated carbon disperse well in the THF solvent with a high dielectric

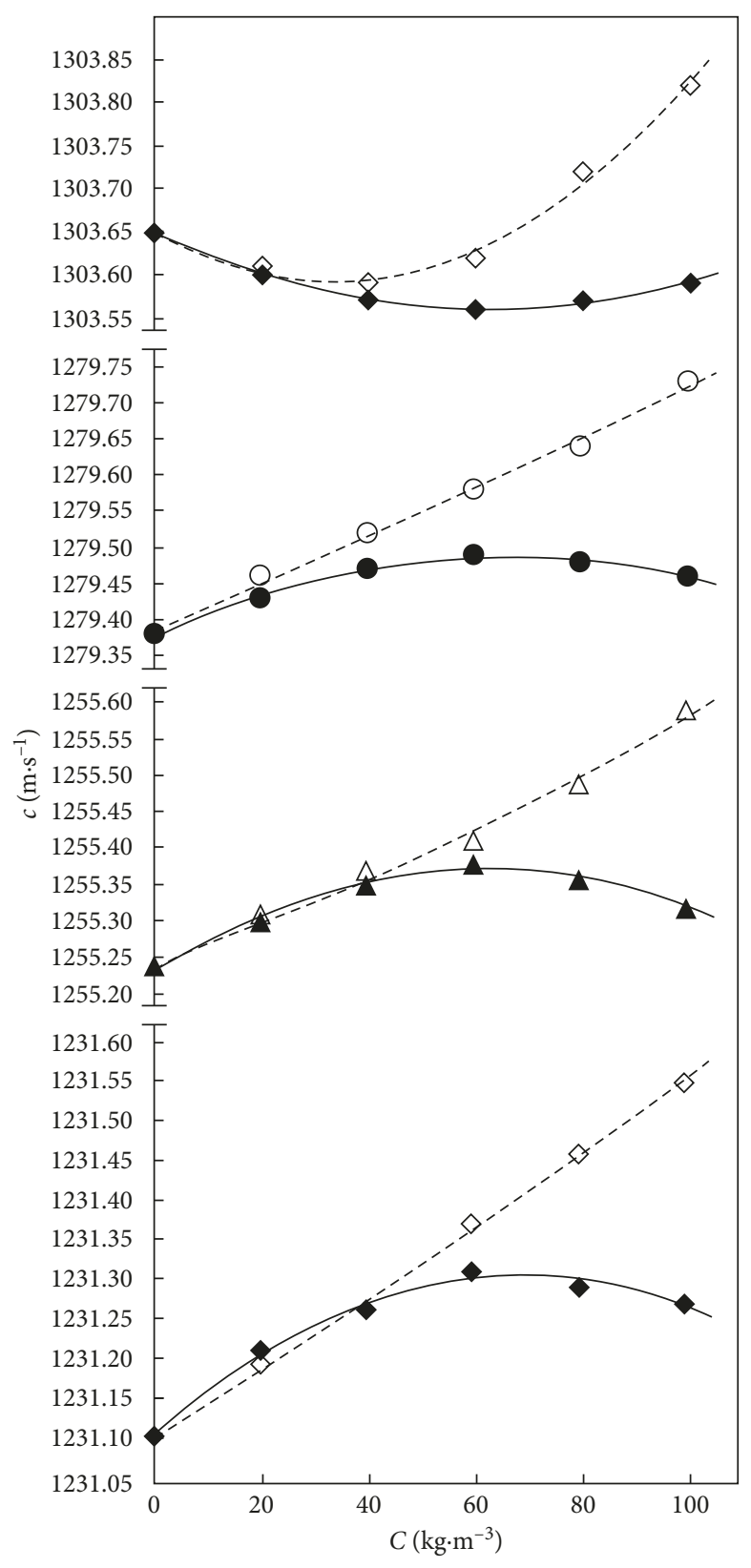

FIGURE 2: Comparative representation of the speeds of sound of binary $\mathrm{xGnP}+\mathrm{THF}$ and $\mathrm{AC}+\mathrm{THF}$ systems versus concentrations of solute at various temperatures, $T(\mathrm{~K})$ : filled diamond, 293.15; filled circle, 298.15; filled triangle, 303.15; filled square, 308.15; for xGnP: open diamond, 293.15; open circle, 298.15; open triangle, 303.15; open square, 308.15; for AC: solid line, dashed line; polynomial correlated values.

conductivity because it is known that they are miscible in high dielectric liquids, with low viscosity, low melting point, and high solubility for inorganic salts [36].

Tables 3 and 4 present experimental results for the same thermophysical properties of $\mathrm{AC}$ and $\mathrm{xGnP}$ in THF solvent measured as a function of their specific concentrations at different temperatures.

Figures 1-3 present the comparison of the refractive indices, speeds of sound, and densities experimental and 


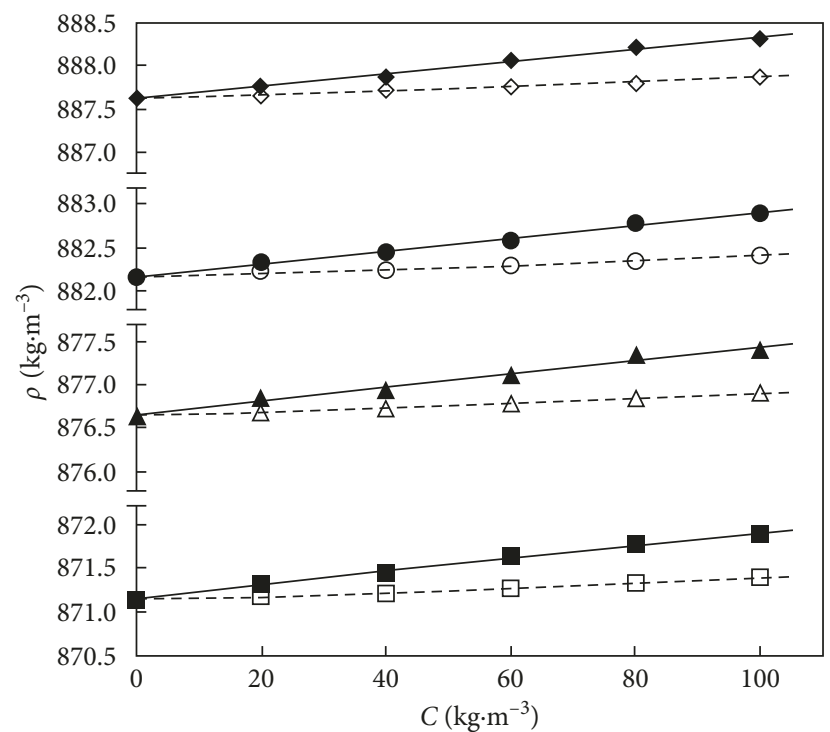

Figure 3: Comparative representation of the density of binary $\mathrm{xGnP}+\mathrm{THF}$ and $\mathrm{AC}+\mathrm{THF}$ systems versus concentration of the solute at various temperatures, $T(\mathrm{~K})$ : filled diamond, 293.15; filled circle, 298.15; filled triangle, 303.15; filled square, 308.15; for $\mathrm{xGnP}$ : open diamond, 293.15; open circle, 298.15; open triangle, 303.15; open square, 308.15; for AC: solid line, dashed line; polynomial correlated values.

TABLE 5: Calculated values of the acoustic impedance $Z$, adiabatic compressibility $k_{\mathrm{S}}$, space-filling factor $S$, specific refraction $r_{\mathrm{D}}$, and relaxation strength $r$ at various temperatures $T$ and specific concentrations $C$ of AC for the system AC+THF.

\begin{tabular}{|c|c|c|c|c|c|}
\hline$T(\mathrm{~K})$ & $Z\left(10^{-5} \cdot \mathrm{kg} \cdot \mathrm{m}^{2} \cdot \mathrm{s}^{1}\right)$ & $k_{S}\left(10^{10} \cdot \mathrm{m}^{-2} \cdot \mathrm{N}^{1}\right)$ & $S$ & $r_{D}\left(10^{3} \cdot \mathrm{m}^{-3} \cdot \mathrm{kg}^{1}\right)$ & $r$ \\
\hline \multicolumn{6}{|c|}{$C\left(\mathrm{~kg} \cdot \mathrm{m}^{-3}\right)=0$} \\
\hline 293.15 & 11.57145 & 6.62904 & 0.24633 & 0.27752 & 0.33613 \\
\hline 298.15 & 11.28617 & 6.92554 & 0.24491 & 0.27762 & 0.36062 \\
\hline 303.15 & 11.00393 & 7.23978 & 0.24348 & 0.27775 & 0.38452 \\
\hline 308.15 & 10.72460 & 7.57400 & 0.24206 & 0.27787 & 0.40797 \\
\hline \multicolumn{6}{|c|}{$C\left(\mathrm{~kg} \cdot \mathrm{m}^{-3}\right)=20$} \\
\hline 293.15 & 11.57162 & 6.62915 & 0.24633 & 0.27750 & 0.33617 \\
\hline 298.15 & 11.28752 & 6.92428 & 0.24491 & 0.27761 & 0.36054 \\
\hline 303.15 & 11.00505 & 7.23864 & 0.24349 & 0.27775 & 0.38445 \\
\hline 308.15 & 10.72588 & 7.57255 & 0.24208 & 0.27787 & 0.40788 \\
\hline \multicolumn{6}{|c|}{$C\left(\mathrm{~kg} \cdot \mathrm{m}^{-3}\right)=40$} \\
\hline 293.15 & 11.57223 & 6.62891 & 0.24633 & 0.27749 & 0.33619 \\
\hline 298.15 & 11.28831 & 6.92347 & 0.24492 & 0.27761 & 0.36048 \\
\hline 303.15 & 11.00633 & 7.23745 & 0.24350 & 0.27773 & 0.38439 \\
\hline 308.15 & 10.72686 & 7.57142 & 0.24208 & 0.27787 & 0.40781 \\
\hline \multicolumn{6}{|c|}{$C\left(\mathrm{~kg} \cdot \mathrm{m}^{-3}\right)=60$} \\
\hline 293.15 & 11.57302 & 6.62830 & 0.24634 & 0.27748 & 0.33616 \\
\hline 298.15 & 11.28961 & 6.92235 & 0.24492 & 0.27760 & 0.36042 \\
\hline 303.15 & 11.00743 & 7.23650 & 0.24351 & 0.27772 & 0.38435 \\
\hline 308.15 & 10.72856 & 7.56955 & 0.24209 & 0.27786 & 0.40771 \\
\hline \multicolumn{6}{|c|}{$C\left(\mathrm{~kg} \cdot \mathrm{m}^{-3}\right)=80$} \\
\hline 293.15 & 11.57443 & 6.62699 & 0.24634 & 0.27747 & 0.33606 \\
\hline 298.15 & 11.29078 & 6.92131 & 0.24493 & 0.27759 & 0.36036 \\
\hline 303.15 & 11.00876 & 7.23516 & 0.24351 & 0.27771 & 0.38428 \\
\hline 308.15 & 10.72996 & 7.56801 & 0.24209 & 0.27785 & 0.40762 \\
\hline \multicolumn{6}{|c|}{$C\left(\mathrm{~kg} \cdot \mathrm{m}^{-3}\right)=100$} \\
\hline 293.15 & 11.57623 & 6.62545 & 0.24635 & 0.27746 & 0.33596 \\
\hline 298.15 & 11.29247 & 6.91979 & 0.24493 & 0.27757 & 0.36027 \\
\hline 303.15 & 11.01039 & 7.23351 & 0.24352 & 0.27770 & 0.38418 \\
\hline 308.15 & 10.73160 & 7.56630 & 0.24210 & 0.27783 & 0.40753 \\
\hline
\end{tabular}


TABLE 6: Calculated values of the acoustic impedance $Z$, adiabatic compressibility $k_{\mathrm{S}}$, space-filling factor $S$, specific refraction $r_{\mathrm{D}}$, and relaxation strength $r$ at various temperatures $T$ and specific concentrations $C$ of $\mathrm{xGnP}$ for the system $\mathrm{xGnP}+\mathrm{THF}$.

\begin{tabular}{|c|c|c|c|c|c|}
\hline$T(\mathrm{~K})$ & $Z\left(10^{-5} \cdot \mathrm{kg} \cdot \mathrm{m}^{2} \cdot \mathrm{s}^{1}\right)$ & $k_{\mathrm{S}}\left(10^{9} \cdot \mathrm{m}^{-2} \cdot \mathrm{N}^{1}\right)$ & $S$ & $r_{\mathrm{D}}\left(10^{3} \cdot \mathrm{m}^{-3} \cdot \mathrm{kg}^{1}\right)$ & $r$ \\
\hline \multicolumn{6}{|c|}{$C\left(\mathrm{~kg} \cdot \mathrm{m}^{-3}\right)=0$} \\
\hline 293.15 & 11.57146 & 6.62904 & 0.24633 & 0.27752 & 0.33613 \\
\hline 298.15 & 11.28618 & 6.92554 & 0.24491 & 0.27762 & 0.36062 \\
\hline 303.15 & 11.00394 & 7.23978 & 0.24348 & 0.27775 & 0.38452 \\
\hline 308.15 & 10.72460 & 7.57400 & 0.24206 & 0.27787 & 0.40797 \\
\hline \multicolumn{6}{|c|}{$C\left(\mathrm{~kg} \cdot \mathrm{m}^{-3}\right)=20$} \\
\hline 293.15 & 11.57284 & 6.62851 & 0.24612 & 0.27723 & 0.33618 \\
\hline 298.15 & 11.28879 & 6.92366 & 0.24469 & 0.27732 & 0.36057 \\
\hline 303.15 & 11.00710 & 7.23735 & 0.24326 & 0.27742 & 0.38446 \\
\hline 308.15 & 10.72778 & 7.57108 & 0.24186 & 0.27758 & 0.40786 \\
\hline \multicolumn{6}{|c|}{$C\left(\mathrm{~kg} \cdot \mathrm{m}^{-3}\right)=40$} \\
\hline 293.15 & 11.57414 & 6.62792 & 0.24597 & 0.27703 & 0.33621 \\
\hline 298.15 & 11.29056 & 6.92237 & 0.24453 & 0.27711 & 0.36053 \\
\hline 303.15 & 11.00879 & 7.23595 & 0.24307 & 0.27718 & 0.38441 \\
\hline 308.15 & 10.72969 & 7.56943 & 0.24178 & 0.27745 & 0.40781 \\
\hline \multicolumn{6}{|c|}{$C\left(\mathrm{~kg} \cdot \mathrm{m}^{-3}\right)=60$} \\
\hline 293.15 & 11.57639 & 6.62667 & 0.24601 & 0.27702 & 0.33622 \\
\hline 298.15 & 11.29252 & 6.92105 & 0.24456 & 0.27710 & 0.36051 \\
\hline 303.15 & 11.01106 & 7.23428 & 0.24313 & 0.27719 & 0.38438 \\
\hline 308.15 & 10.73259 & 7.56707 & 0.24179 & 0.27739 & 0.40776 \\
\hline \multicolumn{6}{|c|}{$C\left(\mathrm{~kg} \cdot \mathrm{m}^{-3}\right)=80$} \\
\hline 293.15 & 11.57857 & 6.62538 & 0.24615 & 0.27713 & 0.33621 \\
\hline 298.15 & 11.29499 & 6.91959 & 0.24471 & 0.27721 & 0.36052 \\
\hline 303.15 & 11.01378 & 7.23262 & 0.24329 & 0.27730 & 0.38440 \\
\hline 308.15 & 10.73414 & 7.56611 & 0.24192 & 0.27750 & 0.40778 \\
\hline \multicolumn{6}{|c|}{$C\left(\mathrm{~kg} \cdot \mathrm{m}^{-3}\right)=100$} \\
\hline 293.15 & 11.57992 & 6.62450 & 0.24655 & 0.27755 & 0.33619 \\
\hline 298.15 & 11.29622 & 6.91895 & 0.24509 & 0.27760 & 0.36054 \\
\hline 303.15 & 11.01430 & 7.23250 & 0.24371 & 0.27777 & 0.38444 \\
\hline 308.15 & 10.73532 & 7.56540 & 0.24232 & 0.27792 & 0.40780 \\
\hline
\end{tabular}

polynomial correlated values as a function of composition of $\mathrm{xGnP}$ and $\mathrm{AC}$ in the $\mathrm{xGnP}+\mathrm{THF}$ and $\mathrm{AC}+\mathrm{THF}$ binary mixed solutions.

The polynomial equation used for the correlations of the measured and calculated properties in both systems is of the following type:

$$
F(Y)=\sum_{i=1}^{n} A_{i} C^{i-1}
$$

where $C$ is the specific concentration $\left(\mathrm{kg} \cdot \mathrm{m}^{-3}\right)$ and $Y$ is the measured physicochemical property.

The refractive index variation by concentration of the activated carbon and exfoliated graphite nanoplatelet solutes in THF is presented in Figure 1.

The refractive index behaviour decreased in the $\mathrm{xGnP}+\mathrm{THF}$ or $\mathrm{AC}+\mathrm{THF}$ mixtures at the same solute composition by raising the temperature. The refractive index values increase by the temperature in the $\mathrm{xGnP}+\mathrm{THF}$ system at $\mathrm{xGnP}$ concentrations bigger than $90 \mathrm{~kg} \cdot \mathrm{m}^{-3}$. The refractive index values rise very slightly by rising the composition of AC solute in the THF organic solvent at all the studied temperatures, too. In the $\mathrm{xGnP}+\mathrm{THF}$ mixture, a decrease of the refractive index values by increasing up to $C=60 \mathrm{~kg} \cdot \mathrm{m}^{-3}(\mathrm{xGnP})$ composition is noticed, followed by an increase up to $C=100 \mathrm{~kg} \cdot \mathrm{m}^{-3}$.
The location of oxygen functional groups at the $\mathrm{xGnP}$ edges plays an important role in interactions [37], the number of edges, plane surfaces, defects, and the (xGnP) crystallite dimension, inducing significant differences by comparison with the other studied material activated carbon.

In Figure 2, it is presented the variation of experimental values of speed of sound and its correlation with the solute composition in $\mathrm{xGnP}+\mathrm{THF}$ and $\mathrm{AC}+\mathrm{THF}$ studied mixtures.

Figure 2 shows the speeds of sound variation in the AC + THF binary system, which increases by increasing the temperature between 298.15 and $308.15 \mathrm{~K}$. In the same system AC + THF, the speed of sound values decrease up to $60 \mathrm{~kg} \cdot \mathrm{m}^{-3}$ and rise at $293.15 \mathrm{~K}$, up to $100 \mathrm{~kg} \cdot \mathrm{m}^{-3}$ with a different slope. The speed of sound values in $\mathrm{xGnP}+\mathrm{THF}$ system varies in a similar way at $293.15 \mathrm{~K}$, increasing up to $C=60 \mathrm{~kg} \cdot \mathrm{m}^{-3}$, then decrease slowly by increasing the concentration. The speed of sound variation at the three studied temperatures $298.15,303.15$, and $308.15 \mathrm{~K}$ is similar as in $\mathrm{AC}+\mathrm{THF}$ binary mixture. The values of speed of sound in $x \mathrm{GnP}+\mathrm{THF}$ mixtures differ than those obtained for the $\mathrm{AC}+\mathrm{THF}$ system. With regard to the slope, this strongly decreases at 298.15, 303.15, and $308.15 \mathrm{~K}$. The behaviour of speed of sound values by rising $\mathrm{xGnP}$ or AC solute 


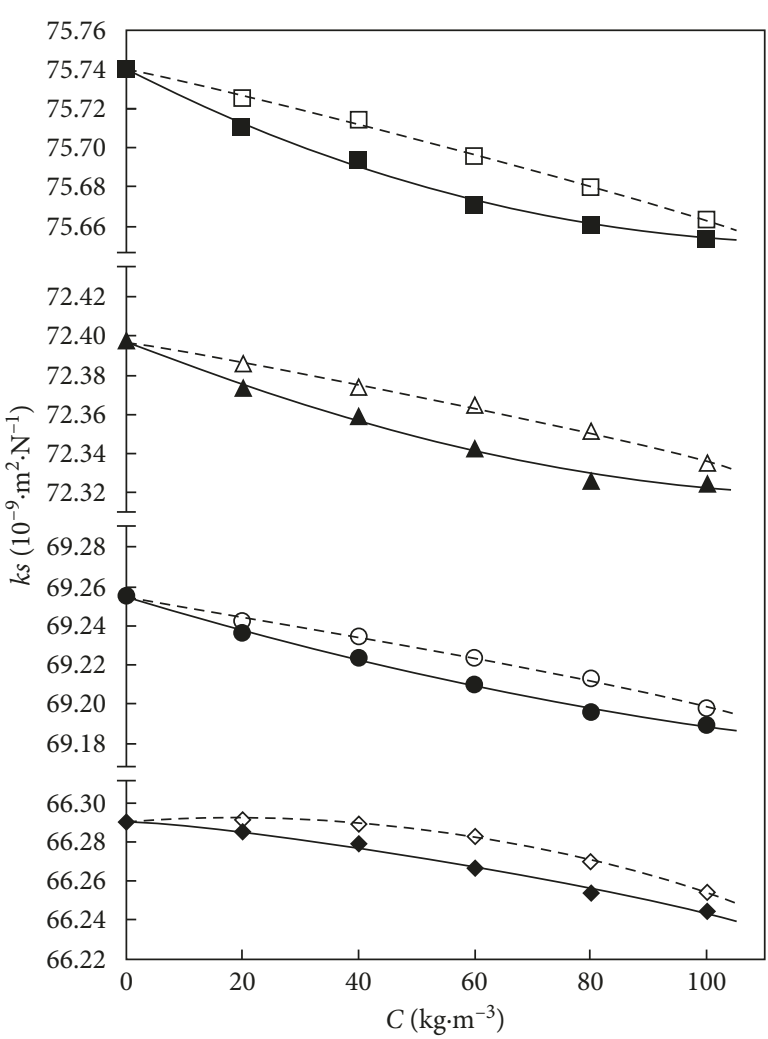

FIgURE 4: Comparative representation of the isentropic compressibility of binary $\mathrm{xGnP}+\mathrm{THF}$ and $\mathrm{AC}+\mathrm{THF}$ systems versus concentrations of solute at various temperatures, $T(\mathrm{~K})$ : filled diamond, 293.15; filled circle, 298.15; filled triangle, 303.15; filled square, 308.15; for xGnP: open diamond, 293.15; open circle, 298.15; open triangle, 303.15 ; open square, 308.15 ; for AC: solid line, dashed line; polynomial correlated values.

concentration shows that the existence of powerful solutesolvent interactions [38] via dipole-dipole ones, which in the domain of studied compositions, can produce displacements of nuclei and electrons. In the $\mathrm{xGnP}+\mathrm{THF}$ mixture, these interactions increase/intensify because the speed of sound slightly decreasing by temperature is much more in the $\mathrm{xGnP}+\mathrm{THF}$ system in comparison with that in $\mathrm{AC}+\mathrm{THF}$. The thermal energy generated by the increase of the temperature contributes to possible bond breakings and weakens the molecular forces in both studied systems.

The variation of obtained data for exfoliated graphite nanoplatelets and activated carbon in THF organic solvent as a function of the solute composition is presented in Figure 3.

In the mixed binary solutions of $\mathrm{AC}$ or $\mathrm{xGnP}+\mathrm{THF}$ by rising the temperature at the same solute composition, the density obtained values decrease as it can be observed from Figure 3 . The density values in the $\mathrm{xGnP}+\mathrm{THF}$ and $\mathrm{AC}+\mathrm{THF}$ mixtures rise by rising $\mathrm{xGnP}$ and $\mathrm{AC}$ specific compositions, up to $C=100 \mathrm{~kg} \cdot \mathrm{m}^{-3}$.

The density of the system $\mathrm{xGnP}+\mathrm{THF}$ increases in comparison with that of the AC + THF system, probably due

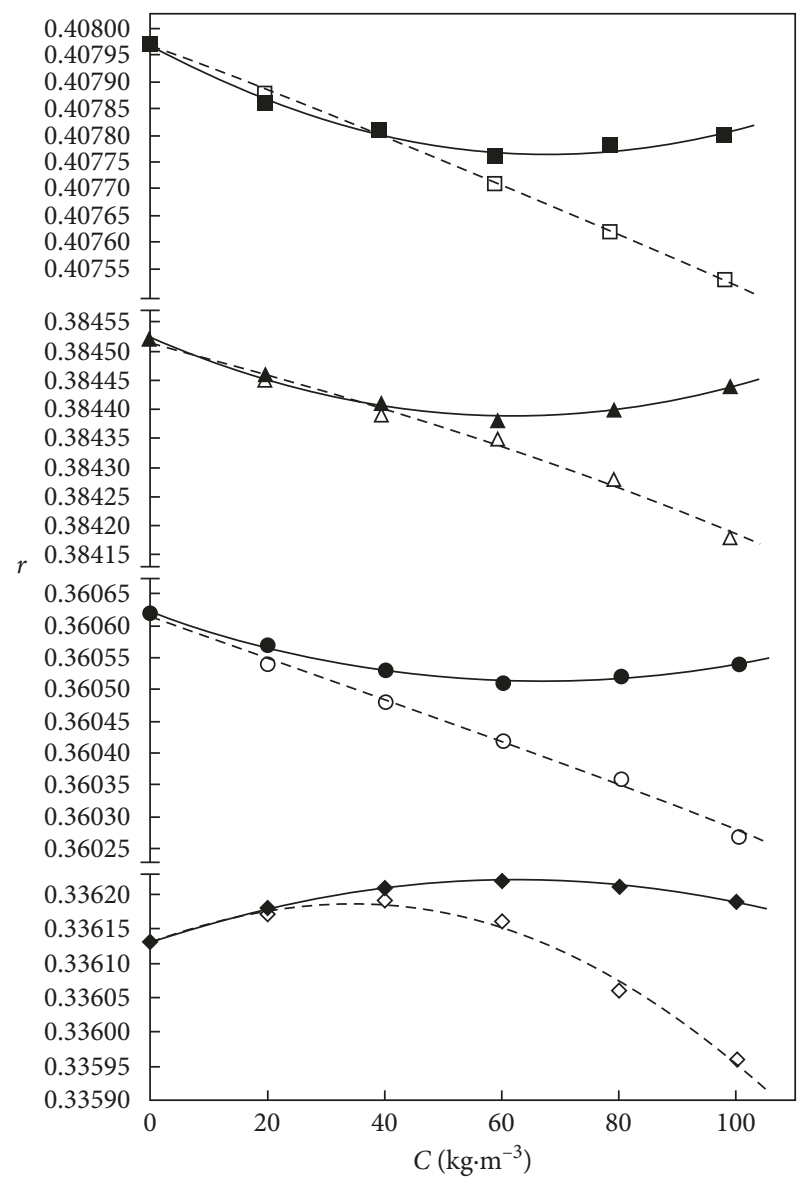

FIgURE 5: Comparative representation of the relaxation strength of binary $\mathrm{xGnP}+\mathrm{THF}$ and AC + THF systems versus concentration of solute at various temperatures, $T(\mathrm{~K})$ : filled diamond, 293.15; filled circle, 298.15; filled triangle, 303.15; filled square, 308.15; for $\mathrm{xGnP}$ : open diamond, 293.15; open circle, 298.15; open triangle, 303.15; open square, 308.15; for AC: solid line, dashed line; polynomial correlated values.

to stronger interactions between $\mathrm{THF}$ and $\mathrm{xGnP}$ compounds than in those between THF and AC compounds. A more pronounced slope of the solute concentration versus density can be mentioned in the $\mathrm{xGnP}+\mathrm{THF}$ system in comparison with the AC + THF one, based on the interactions occurring between THF and carbon-based nanomaterials, which rise the density by rising the solute specific composition in the mixed solution. This behaviour can be explained by several opposite effects. It can be assumed that dipole-dipole interactions, dispersion forces, and hydrogen bonds are the most important forces that can appear between these unlike molecules [39].

The values of isentropic compressibility empirically evaluated [14], acoustic impedance, space-filling factor, specific refraction, and relaxation strength were computed from experimental data. Table 5 presents measured and derived thermophysical properties as function of AC specific composition fraction in THF solvent at different temperatures. 
TABLE 7: The slope and intercept parameters obtained for density, speed of sound, refractive index, isentropic compressibility, and relaxation strength in binary AC + THF mixtures.

\begin{tabular}{|c|c|c|c|c|}
\hline$T(\mathrm{~K})$ & 293.15 & 298.15 & 303.15 & 308.15 \\
\hline \multicolumn{5}{|c|}{ Density } \\
\hline Slope & 0.068240877 & 0.002428571 & 0.002742857 & 0.002471429 \\
\hline \multicolumn{5}{|c|}{$\begin{array}{l}882.1519048 \\
\text { Speed of sound }\end{array}$} \\
\hline Slope & 0.00172857 & 0.003357143 & 0.003328571 & 0.004528571 \\
\hline \multicolumn{5}{|c|}{ Refractive index } \\
\hline Slope & 0.000000314 & 0.000000429 & 0.000000571 & 0.000000657 \\
\hline Intercept & 1.407304286 & $\begin{array}{l}1.404641905 \\
\text { Isentropic compressibility }\end{array}$ & 1.401984762 & 1.399330476 \\
\hline Slope & -0.000035771 & -0.0000554 & -0.000061057 & -0.000077129 \\
\hline Intercept & \multicolumn{3}{|c|}{ Relaxation strength } & 7.574161429 \\
\hline Slope & -0.000001729 & -0.000003357 & -0.000003214 & -0.00000440 \\
\hline Intercept & 0.336198095 & 0.36061619 & 0.384522381 & 0.407973333 \\
\hline
\end{tabular}

TABLE 8: The slope and intercept parameters obtained for density, speed of sound, refractive index, isentropic compressibility, and relaxation strength in binary $\mathrm{xGnP}+\mathrm{THF}$ mixtures.

\begin{tabular}{|c|c|c|c|c|}
\hline$T(\mathrm{~K})$ & 293.15 & 298.15 & 303.15 & 308.15 \\
\hline \multicolumn{5}{|c|}{ Density } \\
\hline Slope & 0.007157143 & 0.007342857 & 0.007828571 & 0.007614286 \\
\hline \multicolumn{5}{|c|}{ Speed of sound } \\
\hline Slope & -0.00057143 & 0.000814286 & 0.000871429 & 0.001628571 \\
\hline \multicolumn{5}{|c|}{$\begin{array}{l}1279.410952 \\
\text { Refractive index }\end{array}$} \\
\hline Slope & 0.000003300 & 0.000002714 & 0.000003429 & 0.000003871 \\
\hline \multicolumn{5}{|c|}{ Isentropic compressibility } \\
\hline Slope & -0.000476286 & -0.000664 & -0.000746571 & -0.00086100 \\
\hline Intercept & 66.29384762 & $\begin{array}{l}\quad 69.251800 \\
\text { Relaxation strength }\end{array}$ & 72.39146190 & 75.73153333 \\
\hline Slope & 0.000000571 & -0.000000814 & -0.000000871 & -0.000001629 \\
\hline Intercept & 0.336161429 & 0.360589048 & 0.384478571 & 0.407911429 \\
\hline
\end{tabular}

The computed physicochemical parameters in the $x \mathrm{GnP}+\mathrm{THF}$ mixed binary solutions are presented in the same conditions in Table 6.

Figures 4 and 5 illustrate the compared variations of $\mathrm{xGnP}$ or $\mathrm{AC}+\mathrm{THF}$ binary mixtures of the estimated and correlated values of isentropic compressibility $k_{\mathrm{S}}$ and relaxation strength $r$ of the solute composition.

The isentropic compressibility values of the binary $\mathrm{AC}+\mathrm{THF}$ system (Figure 4) increase by rising the temperature to the same solute composition. In both systems, the isentropic compressibility values decrease with rising the solute compositions up to a $\mathrm{C}$ value of $100 \mathrm{~kg} \cdot \mathrm{m}^{-3}$. A different trend of variation of the concentration in the $\mathrm{AC}+\mathrm{THF}$ system at $293.15 \mathrm{~K}$ was noticed, till $40 \mathrm{~kg} \cdot \mathrm{m}^{-3}$.

The values of the isentropic compressibility for the $\mathrm{xGnP}$ + THF mixture are smaller than the AC+THF compressibility values all over the solute concentration range. The two systems present different values of isentropic compressibility: nanoexfoliated graphite modifying the $\mathrm{xGnP}+\mathrm{THF}$ system strongly than the AC + THF system.
This behaviour of the estimated isentropic compressibility may be the result of several opposite interactions. Dipole-dipole interactions usually improve the dispersion of the structures in a better way than by breaking of molecular clusters. The values of isentropic compressibility in the $\mathrm{xGnP}+\mathrm{THF}$ system are smaller in comparison with those in the $\mathrm{AC}+\mathrm{THF}$ system, the repulsive interaction resulting from the compression of the $\mathrm{C}-\mathrm{H}$ vertical bonds between the nanosheet surfaces $[39,40]$. In the mixture of the AC dispersed in THF solvent, the THF molecules are limited at a single-layer structure on the surface of AC particles, possibly losing some of the solvent-solvent interaction energy, due to the smaller number of adjacent solvent molecules. The isentropic compressibility empirically estimated based on the obtained experimental data seems consistent, having the same sign in both studied binary mixtures [14].

In the $\mathrm{xGnP}+\mathrm{THF}$ and $\mathrm{AC}+\mathrm{THF}$ binary mixtures, the relaxation strength rises by temperature up to a concentration values of $40 \mathrm{~kg} \cdot \mathrm{m}^{-3}$ and $60 \mathrm{~kg} \cdot \mathrm{m}^{-3}$, respectively, for $293.15 \mathrm{~K}$, 
TABLE 9: Fitting parameters $A_{i}$ and correlation coefficient $R^{2}$ obtained for density $\rho$, speed of sound $c$, refractive index $n_{\mathrm{D}}$, isentropic compressibility $k_{\mathrm{S}}$, and relaxation strength $r$ along with the absolute average percentage deviation (AAD\%) for binary AC + THF mixtures. ${ }^{\text {a }}$

\begin{tabular}{|c|c|c|c|c|c|c|}
\hline$T(\mathrm{~K})$ & $C\left(\mathrm{~kg} \cdot \mathrm{m}^{-3}\right)$ & $A_{1}\left(\mathrm{~kg} \cdot \mathrm{m}^{-3}\right)$ & $A_{2}\left(\mathrm{~kg}^{0} \cdot \mathrm{m}^{0}\right)$ & $A_{3}\left(\mathrm{~kg}^{-1} \cdot \mathrm{m}^{3}\right)$ & $R^{2}$ & $\mathrm{AAD} \%$ \\
\hline \multicolumn{7}{|c|}{$\rho\left(\mathrm{kg} \cdot \mathrm{m}^{-3}\right)$} \\
\hline 293.15 & $0-100$ & 887.62 & 0.0021304 & 0.0000031 & 0.99401 & 0.008 \\
\hline 298.15 & $0-100$ & 882.17 & 0.0014464 & 0.0000098 & 0.99356 & 0.009 \\
\hline 303.15 & $0-100$ & 876.64 & 0.0024750 & 0.0000027 & 0.99821 & 0.009 \\
\hline 308.15 & $0-100$ & 871.14 & 0.0014446 & 0.0000103 & 0.99775 & 0.009 \\
\hline$T(\mathrm{~K})$ & $C\left(\mathrm{~kg} \cdot \mathrm{m}^{-3}\right)$ & $A_{1}\left(\mathrm{~kg}^{0} \cdot \mathrm{m}^{-1} \cdot \mathrm{s}\right)$ & $\begin{array}{c}A_{2}\left(\mathrm{~kg} \cdot \mathrm{m}^{-4} \cdot \mathrm{s}\right) \\
\quad c\left(\mathrm{~m} \cdot \mathrm{s}^{-1}\right)\end{array}$ & $A_{3}\left(\mathrm{~kg}^{2} \cdot \mathrm{m}^{-7} \cdot \mathrm{s}\right)$ & $R^{2}$ & $\mathrm{AAD} \%$ \\
\hline 293.15 & $0-100$ & 1303.65 & -0.003539 & 0.000053 & 0.98967 & 0.005 \\
\hline 298.15 & $0-100$ & 1279.39 & 0.003134 & 0.000002 & 0.99545 & 0.008 \\
\hline 303.15 & $0-100$ & 1255.25 & 0.002302 & 0.000010 & 0.99115 & 0.009 \\
\hline 308.15 & $0-100$ & 1231.10 & 0.004171 & 0.000004 & 0.99825 & 0.011 \\
\hline$T(\mathrm{~K})$ & $C\left(\mathrm{~kg} \cdot \mathrm{m}^{-3}\right)$ & $A_{1}$ & $A_{2} \cdot 10^{5}$ & $A_{3} \cdot 10^{7}$ & $R^{2}$ & $\mathrm{AAD} \%$ \\
\hline \multicolumn{7}{|c|}{$n_{\mathrm{D}}$} \\
\hline 293.15 & $0-100$ & 1.40731 & -0.000000087 & 0.000000004 & 0.98483 & 0.0001 \\
\hline 298.15 & $0-100$ & 1.40464 & 0.000000652 & -0.000000002 & 0.98661 & 0.0001 \\
\hline 303.15 & $0-100$ & 1.40198 & 0.000000795 & -0.000000002 & 0.99235 & 0.0001 \\
\hline 308.15 & $0-100$ & 1.39932 & 0.000001282 & -0.000000006 & 0.97686 & 0.0002 \\
\hline \multicolumn{7}{|c|}{$k_{\mathrm{S}}\left(10^{10} \cdot \mathrm{m}^{2} \cdot \mathrm{N}^{-1}\right)$} \\
\hline 293.15 & $0-100$ & 6.62902 & 0.000020166 & -0.000000559 & 0.99868 & 0.001 \\
\hline 298.15 & $0-100$ & 6.92543 & -0.000045489 & -0.000000099 & 0.99601 & 0.001 \\
\hline 303.15 & $0-100$ & 7.23971 & -0.000046995 & -0.000000141 & 0.99739 & 0.001 \\
\hline 308.15 & $0-100$ & 7.57399 & -0.000064004 & -0.000000131 & 0.99836 & 0.001 \\
\hline$T(\mathrm{~K})$ & $C\left(\mathrm{~kg} \cdot \mathrm{m}^{-3}\right)$ & $A_{1}\left(\mathrm{~kg}^{0} \cdot \mathrm{m}^{0}\right)$ & $A_{2}\left(\mathrm{~kg}^{-1} \cdot \mathrm{m}^{3}\right)$ & $A_{3}\left(\mathrm{~kg}^{-2} \cdot \mathrm{m}^{-6}\right)$ & $R^{2}$ & $\mathrm{AAD} \%$ \\
\hline \multicolumn{7}{|c|}{$r$} \\
\hline 293.15 & $0-100$ & 0.33613 & 0.000003539 & -0.000000053 & 0.98967 & 0.002 \\
\hline 298.15 & $0-100$ & 0.36061 & -0.000003134 & -0.000000002 & 0.99545 & 0.002 \\
\hline 303.15 & $0-100$ & 0.38451 & -0.000002366 & -0.000000008 & 0.99004 & 0.003 \\
\hline 308.15 & $0-100$ & 0.40797 & -0.000004043 & -0.000000004 & 0.99899 & 0.001 \\
\hline
\end{tabular}

${ }^{\mathrm{a}} A_{\mathrm{i}}$ and $R^{2}$ were obtained from (2).

as presented in Figure 5. The relaxation strength decreases at temperatures of $298.15,303.15$, and 308.15 in $\mathrm{AC}+\mathrm{THF}$ mixture.

Relaxation strength values in the $\mathrm{xGnP}+\mathrm{THF}$ system decrease up to a solute composition of approximately $60 \mathrm{~kg} \cdot \mathrm{m}^{-3}$ at the temperatures from 298.15 up to $308.15 \mathrm{~K}$ and rise by raising the solute composition, which reflects a predominance of the molecular interactions [41]. The computed slope and intercept of simple polynomial equation with "statistical functions" from Excel for all properties from the presented figures are shown in Tables 7 and 8.

The values for the absolute average percentage deviation (AAD\%) obtained from the correlated of equation (1) of $\rho, c$, $n_{\mathrm{D}}, k_{\mathrm{S}}$ and $r$ as a function of composition have been computed.

The following relationship has been used for computing the absolute average percentage deviation (AAD\%):

$$
\operatorname{AAD}(Y)=\frac{100}{N} \sum_{i}^{n}\left|\frac{Y_{\text {Expt. }}-Y_{\text {Calc. }}}{Y_{\text {Expt. }}}\right| \text {, }
$$

where $N$ is the experimental data number. The subscripts "Expt." and "Calc." are the experimental and calculated property values, respectively.
Fitting parameters $A_{i}$ and $\mathrm{AAD} \%$ values of all the studied temperatures are summarized in Table 9 for AC+THF binary solutions.

Tables 9 and 10 present the calculated values of the $A_{i}$ parameters, correlation coefficient $R^{2}$ obtained for density $\rho$, speed of sound $c$, isentropic compressibility $k_{\mathrm{S}}$, and relaxation strength $r[8,14,15]$, together with the AAD\% calculated from (2) for $\mathrm{AC}+\mathrm{THF}$ and $\mathrm{xGnP}+\mathrm{THF}$ binary mixed solutions.

The absolute average percentage deviation for the physicochemical properties: refractive index, speed of sound, density, isentropic compressibility, and relaxation strength are less than $0.0002,0.011,0.009,0.001$, and $0.003 \%$ for the AC+ THF mixture and less than 0.119 , $0.002,0.003,0.003$, and $0.002 \%$ for the $\mathrm{xGnP}+\mathrm{THF}$ mixture, being well correlated for both systems, as it can be seen from Tables 9 and 10 .

The isentropic compressibility $\left(k_{\mathrm{S}}\right)$ rises by the temperature, but it decreases when the concentration rises.

As shown in Tables 9 and 10 and in Figures 1-5, the values of the thermophysical properties experimentally obtained on the basis of polynomial relation (1) have been correlated with good accuracy.

The thermophysical behaviour of studied carbon-based nanomaterial-mixed solutions is well described by using 
TABLE 10: Fitting parameters $A_{i}$ and correlation coefficient $R^{2}$ obtained for density $\rho$, speed of sound $c$, refractive index $n_{\mathrm{D}}$, isentropic compressibility $k_{\mathrm{S}}$, and relaxation strength $r$ along with the absolute average percentage deviation (AAD\%) for binary $\mathrm{xGnP}+\mathrm{THF}$ mixtures. ${ }^{\mathrm{a}}$

\begin{tabular}{|c|c|c|c|c|c|c|}
\hline$T(\mathrm{~K})$ & $C\left(\mathrm{~kg} \cdot \mathrm{m}^{-3}\right)$ & $A_{1}\left(\mathrm{~kg} \cdot \mathrm{m}^{-3}\right)$ & $A_{2}\left(\mathrm{~kg}^{0} \cdot \mathrm{m}^{0}\right)$ & $A_{3}\left(\mathrm{~kg}^{-1} \cdot \mathrm{m}^{3}\right)$ & $R^{2}$ & $\mathrm{AAD} \%$ \\
\hline \multicolumn{7}{|c|}{$\rho\left(\mathrm{kg} \cdot \mathrm{m}^{-3}\right)$} \\
\hline 293.15 & $0-100$ & 887.61 & 0.0075589 & -0.0000040 & 0.99423 & 0.002 \\
\hline 298.15 & $0-100$ & 882.17 & 0.0070750 & 0.0000027 & 0.99438 & 0.002 \\
\hline 303.15 & $0-100$ & 876.65 & 0.0086321 & -0.0000080 & 0.98620 & 0.003 \\
\hline 308.15 & 0-100 & 871.14 & 0.0088200 & -0.0000100 & 0.99598 & 0.002 \\
\hline$T(\mathrm{~K})$ & $C\left(\mathrm{~kg} \cdot \mathrm{m}^{-3}\right)$ & $A_{1}\left(\mathrm{~kg}^{0} \cdot \mathrm{m}^{-1} \cdot \mathrm{s}\right)$ & $\begin{array}{l}A_{2}\left(\mathrm{~kg} \cdot \mathrm{m}^{-4} \cdot \mathrm{s}\right) \\
\quad c\left(\mathrm{~m} \cdot \mathrm{s}^{-1}\right)\end{array}$ & $A_{3}\left(\mathrm{~kg}^{2} \cdot \mathrm{m}^{-7} \cdot \mathrm{s}\right)$ & $R^{2}$ & $\mathrm{AAD} \%$ \\
\hline 293.15 & $0-100$ & 1303.65 & -0.002848 & 0.000023 & 0.99669 & 0.001 \\
\hline 298.15 & $0-100$ & 1279.38 & 0.003270 & -0.000025 & 0.99509 & 0.001 \\
\hline 303.15 & $0-100$ & 1255.24 & 0.004354 & -0.000035 & 0.98499 & 0.002 \\
\hline 308.15 & 0-100 & 1231.10 & 0.005780 & -0.000042 & 0.98843 & 0.001 \\
\hline$T(\mathrm{~K})$ & $C\left(\mathrm{~kg} \cdot \mathrm{m}^{-3}\right)$ & $A_{1}$ & $A_{2} \cdot 10^{5}$ & $A_{3} \cdot 10^{7}$ & $R^{2}$ & $\mathrm{AAD} \%$ \\
\hline \multicolumn{7}{|c|}{$n_{\mathrm{D}}$} \\
\hline 293.15 & $0-100$ & 1.40735 & -0.000032012 & 0.000000353 & 0.98442 & 0.086 \\
\hline 298.15 & $0-100$ & 1.40468 & -0.000032420 & 0.000000351 & 0.98895 & 0.084 \\
\hline 303.15 & $0-100$ & 1.40203 & -0.000035411 & 0.000000388 & 0.98336 & 0.119 \\
\hline 308.15 & $0-100$ & 1.39935 & -0.000028093 & 0.000000320 & 0.97351 & 0.092 \\
\hline$T(\mathrm{~K})$ & $C\left(\mathrm{~kg} \cdot \mathrm{m}^{-3}\right)$ & $A_{1}\left(10^{-10} \cdot \mathrm{kg}^{0} \cdot \mathrm{m}^{2} \cdot \mathrm{N}^{-1}\right)$ & $\begin{array}{c}A_{2}\left(10^{-9} \cdot \mathrm{kg}^{-1} \cdot \mathrm{m}^{5} \cdot \mathrm{N}^{-1}\right) \\
k_{\mathrm{S}}\left(10^{-10} \cdot \mathrm{m}^{2} \cdot \mathrm{N}^{-1}\right)\end{array}$ & $A_{3}\left(10^{-9} \cdot \mathrm{kg}^{-2} \cdot \mathrm{m}^{8} \cdot \mathrm{N}^{-1}\right)$ & $R^{2}$ & $\mathrm{AAD} \%$ \\
\hline 293.15 & $0-100$ & 6.6291139 & -0.000273 & -0.000002 & 0.991057 & 0.002 \\
\hline 298.15 & $0-100$ & 6.9255086 & -0.000910 & 0.000002 & 0.996994 & 0.003 \\
\hline 303.15 & $0-100$ & 7.2397718 & -0.001216 & 0.000005 & 0.991389 & 0.003 \\
\hline 308.15 & $0-100$ & 7.5739754 & -0.001478 & 0.000006 & 0.995453 & 0.002 \\
\hline$T(\mathrm{~K})$ & $C\left(\mathrm{~kg} \cdot \mathrm{m}^{-3}\right)$ & $A_{1}\left(\mathrm{~kg}^{0} \cdot \mathrm{m}^{0}\right)$ & $A_{2}\left(\mathrm{~kg}^{-1} \cdot \mathrm{m}^{3}\right)$ & $A_{3}\left(\mathrm{~kg}^{-2} \cdot \mathrm{m}^{-6}\right)$ & $R^{2}$ & $\mathrm{AAD} \%$ \\
\hline \multicolumn{7}{|c|}{$r$} \\
\hline 293.15 & $0-100$ & 0.33613 & 0.000002848 & -0.000000023 & 0.99669 & 0.001 \\
\hline 298.15 & $0-100$ & 0.36062 & -0.000003270 & 0.000000025 & 0.99508 & 0.001 \\
\hline 303.15 & $0-100$ & 0.38453 & -0.000004354 & 0.000000035 & 0.98499 & 0.001 \\
\hline 308.15 & $0-100$ & 0.40797 & -0.000005780 & 0.000000042 & 0.98843 & 0.002 \\
\hline
\end{tabular}

${ }^{\mathrm{a}} A_{i}$ and $R^{2}$ were obtained from (2).

three correlation parameters with polynomial expression (1). The experimental property and computed property values have been then statistically interpreted by analysis of variance "two-factor without replication" by method ANOVA. The obtained values for the both binary mixtures of AC and $\mathrm{xGnP}$ in THF solvent are given in Tables 11 and 12, respectively.

The ANOVA results suggest that the model coefficients are significant if the $F$ value is higher than $F_{\text {crit }}$ value with $P$ value $<0.05$. In ANOVA statistical analysis, for a 95\% confidence level, the "alpha" significance level was used as $5 \%$. In Table 11 , the $F$ values are greater than the corresponding $F_{\text {crit }}$ values of density, speed of sound, refractive index, isentropic compressibility, and relaxation strength in binary $\mathrm{AC}+\mathrm{THF}$ mixtures at different compositions and temperatures, while the $P$ values are much smaller than the "alpha" value for each property $(P<0.05)[42-44]$. In Table 12 , the values of $F<F_{\text {crit }}$, and $P>0.05$ demonstrates an insignificant effect of concentration on the speed of sound and relaxation strength in binary mixture with $\mathrm{xGnP}$. The ANOVA results show that some parameters have a significant influence on the thermophysical properties in the binary mixtures AC and $\mathrm{xGnP}$ with THF solvent.

\section{Conclusions}

The refractive index, speed of sound, density of exfoliated graphite nanoplatelets, and activated carbon dispersed in THF solvent were measured at different temperatures over the 0 to $100 \mathrm{~kg} \cdot \mathrm{m}^{-3}$ concentration domain. The derived physicochemical properties from measured experimental data were calculated, and the absolute average percentage deviation $(\mathrm{AAD} \%)$ values are comparable for both mixtures. In the $\mathrm{xGnP}+\mathrm{THF}$ mixture, the $\mathrm{AAD} \%$ values for the physicochemical parameters such as refractive index, speed of sound, density, isentropic compressibility, and relaxation strength are less than $0.119,0.002,0.003,0.003$, and $0.002 \%$. Also, in the AC+ THF mixture, the AAD\% values for the same physicochemical parameters are less than $0.0002,0.011$, $0.009,0.001$, and $0.003 \%$ being well correlated by polynomial relation with three correlation parameters. Also, the effects of different parameters such as the temperature and concentration in the $\mathrm{AC} / \mathrm{xGnP}+\mathrm{THF}$ binary mixtures have been statistically investigated by the ANOVA method, and the obtained results, in generally, demonstrate their higher significance influence on of the studied thermophysical properties. The theoretical methodology presented in this study might explain the ability of the organic solvent THF to 
TABLE 11: Analysis of variance two-factor without replication for density, speed of sound, refractive index, isentropic compressibility, and relaxation strength in binary AC + THF mixtures.

\begin{tabular}{|c|c|c|c|c|c|c|}
\hline Source of variation & SS & $\mathrm{d} f$ & MS & $F$ & $P$ value & $F_{\text {crit }}$ \\
\hline \multicolumn{7}{|c|}{ Density } \\
\hline Concentration & 0.179183 & 5 & 0.035837 & 408.2658 & $1.81 E-15$ & 2.901295 \\
\hline Temperature & 906.2948 & 3 & 302.0983 & 3441626 & $5.34 E-44$ & 3.287382 \\
\hline Error & 0.001317 & 15 & $8.78 E-05$ & & & \\
\hline Total & 906.4753 & 23 & 906.4753 & & & \\
\hline \multicolumn{7}{|c|}{ Speed of sound } \\
\hline Concentration & 0.300683 & 5 & 0.060137 & 22.98217 & $1.54 E-06$ & 2.901295 \\
\hline Temperature & 17451.79 & 3 & 5817.263 & 2223158 & $1.42 E-42$ & 3.287382 \\
\hline Error & 0.03925 & 15 & 0.002617 & & & \\
\hline Total & 17452.13 & 23 & & & & \\
\hline \multicolumn{7}{|c|}{ Refractive index } \\
\hline Concentration & $6.9 E-09$ & 5 & $1.38 E-09$ & 23 & $1.53 E-06$ & 2.901295 \\
\hline Temperature & 0.000211 & 3 & $7.03 E-05$ & 1172184 & $1.72 E-40$ & 3.287382 \\
\hline Error & $9 E-10$ & 15 & $6 E-11$ & & & \\
\hline Total & 0.000211 & 23 & & & & \\
\hline \multicolumn{7}{|c|}{ Isentropic compressibility } \\
\hline Concentration & $9.34 E-05$ & 5 & $1.87 E-05$ & 39.25078 & $4.28 E-08$ & 2.901295 \\
\hline Temperature & 2.96209 & 3 & 0.987363 & 2074115 & $2.38 E-42$ & 3.287382 \\
\hline Error & $7.14 E-06$ & 15 & $4.76 E-07$ & & & \\
\hline Total & 2.96219 & 23 & & & & \\
\hline \multicolumn{7}{|c|}{ Relaxation strength } \\
\hline Concentration & $2.89 E-07$ & 5 & $5.79 E-08$ & 23.53823 & $1.32 E-06$ & 2.901295 \\
\hline Temperature & 0.017114 & 3 & 0.005705 & 2319295 & $1.03 E-42$ & 3.287382 \\
\hline Error & $3.69 E-08$ & 15 & $2.46 E-09$ & & & \\
\hline Total & 0.017115 & 23 & & & & \\
\hline
\end{tabular}

TABLE 12: Analysis of variance two-factor without replication for density, speed of sound, refractive index, isentropic compressibility, and relaxation strength in binary $\mathrm{xGnP}+\mathrm{THF}$ mixtures.

\begin{tabular}{|c|c|c|c|c|c|c|}
\hline Source of variation & SS & $\mathrm{d} f$ & MS & $F$ & $P$ value & $F_{\text {crit }}$ \\
\hline \multicolumn{7}{|c|}{ Density } \\
\hline Concentration & 1.5783 & 5 & 0.31566 & 816.3621 & $1.03 E-17$ & 2.901295 \\
\hline Temperature & 900.9193 & 3 & 300.3064 & 776654.6 & $3.77 E-39$ & 3.287382 \\
\hline Error & 0.0058 & 15 & 0.000387 & & & \\
\hline Total & 902.5034 & 23 & & & & \\
\hline \multicolumn{7}{|c|}{ Speed of sound } \\
\hline Concentration & 0.022483 & 5 & 0.004497 & 2.034691 & 0.131603 & 2.901295 \\
\hline Temperature & 17449.86 & 3 & 5816.62 & 2631955 & $3.99 E-43$ & 3.287382 \\
\hline Error & 0.03315 & 15 & 0.00221 & & & \\
\hline Total & 17449.92 & 23 & & & & \\
\hline \multicolumn{7}{|c|}{ Refractive index } \\
\hline Concentration & $3.34 E-06$ & 5 & $6.68 E-07$ & 381.4987 & $2.99 E-15$ & 2.901295 \\
\hline Temperature & 0.000209 & 3 & $6.98 E-05$ & 39877.28 & $1.77 E-29$ & 3.287382 \\
\hline Error & $2.63 E-08$ & 15 & $1.75 E-09$ & & & \\
\hline Total & 0.000213 & 23 & & & & \\
\hline \multicolumn{7}{|c|}{ Isentropic compressibility } \\
\hline Concentration & 0.01346 & 5 & 0.002692 & 49.93149 & $8.06 E-09$ & 2.901295 \\
\hline Temperature & 295.8396 & 3 & 98.61318 & 1829148 & $6.11 E-42$ & 3.287382 \\
\hline Error & 0.000809 & 15 & $5.39 E-05$ & & & \\
\hline Total & 295.8538 & 23 & & & & \\
\hline \multicolumn{7}{|c|}{ Relaxation strength } \\
\hline Concentration & $2.25 E-08$ & 5 & $4.5 E-09$ & 2.034691 & 0.131603 & 2.901295 \\
\hline Temperature & 0.01711 & 3 & 0.005703 & 2580691 & $4.62 E-43$ & 3.287382 \\
\hline Error & $3.31 E-08$ & 15 & $2.21 E-09$ & & & \\
\hline Total & 0.01711 & 23 & & & & \\
\hline
\end{tabular}


disperse $\mathrm{xGnP}$ and to stabilize the $\mathrm{xGnP}+\mathrm{THF}$ mixture in comparison with the $\mathrm{AC}+\mathrm{THF}$ one. THF, which disperses carbon-based nanostructures, is one of the best solvents, and its behaviour based on fundamental principles and practical methods is being emphasized in this work, too.

\section{Conflicts of Interest}

The authors declare that they have no conflicts of interest.

\section{Acknowledgments}

This research was performed in the frame of ERA-NET SIIN funded by the European Commission within the 7 th Framework Program and supported by the Romanian Executive Agency for Higher Education and RDI Funding (Unitatea Executiva pentru Finantarea Invatamantului Superior, Cercetarii, Dezvoltarii si Inovarii (UEFISCDI)). The authors thank the National Research \& Development Institute for Chemistry and Petrochemistry ICECHIM of Romania for the financial support. Also, support of the "Ilie Murgulescu" Institute of Physical Chemistry of Romanian Academy by the project EU (ERDF) and Romanian Government Infrastructure POS-CCE O 2.2.1 INFRANANOCHEM (no. 19/200) is gratefully acknowledged.

\section{References}

[1] S. S. Ubarhande, A. S. Burghate, B. N. Berad, and J. D. Turak, "Studies on refractive index of 1,3-diaryl carbamides in different percentage of binary liquid mixture," Rasayan Journal of Chemistry, vol. 4, no. 3, pp. 585-587, 2011.

[2] M. Pumera, "Graphene-based nanomaterials and their electrochemistry," Chemical Society Reviews, vol. 39, no. 11, pp. 4146-4157, 2010.

[3] M. S. Goh and M. Pumera, "The electrochemical response of graphene sheets is independent of the number of layers from a single graphene sheet to multilayer stacked graphene platelets," Chemistry-An Asian Journal, vol. 5, no. 11, pp. 2355-2357, 2010.

[4] Y. Zhu, S. Murali, W. Cai et al., "Graphene and graphene oxide: synthesis, properties, and applications," Advanced Materials, vol. 22, no. 35, pp. 3906-3924, 2010.

[5] E. Radu, A. C. Ion, F. Sirbu, and I. Ion, "Adsorption of endocrine disruptors on exfoliated graphene nanoplatelets," Environmental Engineering \& Management Journal, vol. 14, no. 3, pp. 551-558, 2015.

[6] C. J. Shih, S. Lin, M. S. Strano, and D. Blankschtein, "Understanding the stabilization of liquid-phase-exfoliated graphene in polar solvents: molecular dynamics simulations and kinetic theory of colloid aggregation," Journal of the American Chemical Society, vol. 132, no. 41, pp. 14638-14648, 2010.

[7] K. Tamura, S. Murakami, Y. Akagi, M. Fukumori, and Y. Kawasaki, "Thermodynamic properties of binary mixtures: hexamethylphosphoric triamide + a polar liquid at $25^{\circ} \mathrm{C}$," Journal of Solution Chemistry, vol. 23, no. 2, pp. 263-273, 1994.

[8] I. Ion, F. Sirbu, and A. C. Ion, "Density, refractive index, and ultrasound speed in mixtures of active carbon and exfoliated graphite nanoplatelets dispersed in $\mathrm{N}, \mathrm{N}$-dimethylformamide at temperatures from (293.15 to 318.15) K, Journal of Chemical \& Engineering Data, vol. 58, no. 5, pp. 1212-1222, 2013.
[9] D. F. Emerich and C. G. Tahnos, "The pinpoint promise of nanoparticle-based drug delivery and molecular diagnosis," Biomolecular Engineering, vol. 23, no. 4, pp. 171-184, 2006.

[10] L. Farmen, Nanotechnology Applications for Clean Water, William Andrew Inc., Norwich, NY, USA, 2009.

[11] Q. Zaib, I. Khan, N. Saleh, J. V. Flora, Y. G. Park, and Y. Yoon, "Removal of bisphenol A and 17- $\beta$-estradiol by single-walled carbon nanotubes in aqueous solution: adsorption and molecular modeling," Water, Air, and Soil Pollution, vol. 223, no. 6, pp. 3281-3293, 2012.

[12] X. M. Yan, B. Y. Shi, J. J. Lu, C. H. Feng, D. S. Wang, and H. X. Tang, "Adsorption and desorption of atrazine on carbon nanotubes," Journal of Colloid and Interface Science, vol. 321, no. 1 , pp. 30-38, 2008.

[13] J. Xu, L. Wang, and Y. Zhu, "Decontamination of bisphenol A from aqueous solution by graphene adsorption," Langmuir, vol. 28 , no. 22 , pp. 8418-8425, 2012.

[14] I. Ion, F. Sirbu, and A. C. Ion, "Thermophysical investigations of exfoliated graphite nanoplatelets and active carbon in binary aqueous environments at different temperatures," Journal of Materials Science, vol. 50, no. 2, pp. 587-598, 2015.

[15] F. Sirbu, I. Ion, and A. C. Ion, "Comparative thermodynamic study on exfoliated graphite nanoplatelets systems dispersed in dimethylformamide and water at $\mathrm{T}=(293.15,298.15$ and 303.15) K," in New Applications of Nanomaterials: Micro and Nanoengineering, vol. 22, pp. 137-152, Romanian Academy, Bucharest, Romania, 2014.

[16] N. Ebrahimi and R. Sadeghi, "Volumetric and compressibility behaviour of poly(propylene glycol)-amino acid aqueous solutions at different temperatures," Journal of Chemical Thermodynamics, vol. 90, pp. 129-139, 2015.

[17] A. Pal, H. Kumar, R. Maan, H. Kumar Sharma, and S. Sharma, "Solute-solvent interactions of glycine, L-alanine, and L-valine in aqueous 1-methyl imidazolium chloride ionic liquid solutions in the temperature interval (288.15 to 308.15$) \mathrm{K}$," Journal of Chemical Thermodynamics, vol. 91, pp. 146-155, 2015.

[18] J. A. Riddick, W. B. Bunger, and T. K. Sakano, Organic Solvents: Physical Properties and Methods of Purification, Wiley, New York, NY, USA, 1988.

[19] C. R. Snelling, CRC Handbook of Chemistry and Physics, CRC Press, Boca Raton, FL, USA, 53rd edition, 2008.

[20] R. K. Ameta, M. Singh, and R. K. Kale, "Comparative study of density, sound velocity and refractive index for (water + alkali metal) phosphates aqueous systems at $\mathrm{T}=(298.15,303.15$, 308.15) K," Journal of Chemical Thermodynamics, vol. 60, pp. 159-168, 2013.

[21] A. Arce, A. Blanco, A. Soto, and I. Vidal, "Densities, refractive indices, and excess molar volumes of the ternary systems water + methanol + 1-octanol and water + ethanol + 1-octanol and their binary mixtures at $298.15 \mathrm{~K}$," Journal of Chemical \& Engineering Data, vol. 38, no. 2, pp. 336-340, 1993.

[22] Evaluation of Measurement Data-Guide to The Expression of Uncertainty in Measurement, Report of Working Group 1 of the Joint Committee for Guides in Metrology, 2008.

[23] T. B. Du, T. B. Du, M. Tang, and Y. P. Chen, "Vapor-liquid equilibria of the binary mixtures of tetrahydrofuran with 2,2,4-trimethylpentane, methylcyclohexane and $n$-heptane at 101.3 kPa," Fluid Phase Equilibria, vol. 192, no. 1-2, pp. 71-83, 2001.

[24] S. Singh, I. Vibhu, M. Gupta, and J. P. Shukla, "Excess acoustical and volumetric properties and the theoretical estimation of the excess thermodynamic functions of binary liquid mixtures," Chinese Journal of Physics, vol. 45, pp. 412-424, 2007. 
[25] V. Belandria, A. H. Mohammadi, and D. Richon, "Volumetric properties of the (tetrahydrofuran + water) and (tetra-n-butyl ammonium bromide + water) systems: experimental measurements and correlations," Journal of Chemical Thermodynamics, vol. 41, no. 12, pp. 1382-1386, 2009.

[26] Texas A\&M University, TRC Data Base for Chemistry and Engineering, Thermodynamic Research Center, Texas A\&M University, College Station, TX, USA, 1993.

[27] A. K. Nain, "Densities and volumetric properties of binary mixtures of tetrahydrofuran with some aromatic hydrocarbons at temperatures from 278.15 to $318.15 \mathrm{~K}$," Journal of Solution Chemistry, vol. 35, no. 10, pp. 1417-1439, 2006.

[28] A. K. Nain, "Inversion of the Kirkwood-Buff theory of solutions: application to tetrahydrofuran + aromatic hydrocarbon binary liquid mixtures," Journal of Solution Chemistry, vol. 37, no. 11, pp. 1541-1559, 2008.

[29] D. S. Wankhede, "Refractive indices for binary mixtures of propylene carbonate," International Journal of Chemical Research, vol. 2, pp. 23-26, 2011.

[30] C. Pan, Q. Ke, G. Ouyang, X. Zhen, Y. Yang, and Z. Huang, "Excess molar volumes and surface tensions of trimethylbenzene with tetrahydrofuran, tetrachloromethane and dimethyl sulfoxide at $298.15 \mathrm{~K}$," Journal of Chemical \& Engineering Data, vol. 49, no. 6, pp. 1839-1842, 2004.

[31] H. Iloukhani, Z. Zoorasna, and R. Soleimani, "Excess molar volumes and speeds of sound of tetrahydrofuran with chloroethanes or chloroethenes at $298.15 \mathrm{~K}$," Physics and Chemistry of Liquids, vol. 43, no. 4, pp. 391-401, 2005.

[32] H. Kumar, R. Kumar, and Dheeraj, "Thermodynamic study of binary liquid mixture of 1,2-dichlorobenzene in tetrahydrofuran at $\mathrm{T}=303.15 \mathrm{~K}$," Indian Journal of Pure and Applied Physics, vol. 1, pp. 260-277, 2011.

[33] P. B. Agarwal and M. L. Narwade, "Ultrasonic and viscometric studies of substituted flavone, isoxazole and pyrazole in $70 \%$ acetone-water mixture," Indian Journal of Chemistry-Section A, vol. 42, pp. 1047-1049, 2003.

[34] R. R. Mishra, "Measurements of the ultrasonic velocity for the organic liquids at various temperatures and concentrations," VSRD Technical \& Non-Technical Journal, vol. 2, pp. 405-412, 2011.

[35] A. Anwar, N. A. Kumar, S. V. Kumar, and A. Shakil, "Molecular interactions in binary mixtures of tetrahydrofuran with alkanols $\left(\mathrm{C}_{6}, \mathrm{C}_{8}, \mathrm{C}_{10}\right)$ : an ultrasonic and volumetric study," Indian Journal of Pure and Applied Physics, vol. 42, pp. 666-673, 2004.

[36] D. Koniosa, M. M. Stylianakisa, E. Stratakisc, and E. Kymakis, "Dispersion behaviour of graphene oxide and reduced graphene oxide," Journal of Colloid and Interface Science, vol. 430, pp. 108-112, 2014.

[37] D. H. Kim, Y. S. Yun, and H. J. Jin, “Difference of dispersion behavior between graphene oxide and oxidized carbon nanotubes in polar organic solvents," Current Applied Physics, vol. 12, no. 3, pp. 637-642, 2012.

[38] K. Venkatramanan, R. Padmanaban, and V. Arumugam, "Acoustic, thermal and molecular interactions of polyethylene glycol (2000, 3000, 6000)," Physics Procedia, vol. 70, pp. 1052-1056, 2015.

[39] F. Chen, Z. Yang, Z. Chen, J. Hu, C. Chen, and J. Cai, "Density, viscosity, speed of sound, excess property and bulk modulus of binary mixtures of $\gamma$-butyrolactone with acetonitrile, dimethyl carbonate, and tetrahydrofuran at temperatures (293.15 to 333.15) K," Journal of Molecular Liquids, vol. 209, pp. 683-692, 2015.
[40] N. Vaisman, H. D. Wagner, and G. Marom, "The role of surfactants in dispersion of carbon nanotube," Advances in Colloid and Interface Science, vol. 128-130, pp. 37-46, 2006.

[41] S. Baluja, S. Baluja, J. Movaliya, J. Movaliya, N. Godvani, and N. Godvani, "Acoustical studies of some derivatives of 1,5benzodiazepines formamide and tetrahydrofuran solutions at 298.15 K," Russian Journal of Physical Chemistry A, vol. 8, no. 13, pp. 2223-2229, 2009.

[42] E. Ahmadinia, M. Zargar, M. R. Karim, M. Abdelaziz, and P. Shafigh, "Using waste plastic bottles as additive for stone mastic asphalt," Materials \& Design, vol. 32, no. 10, pp. 4844-4849, 2011.

[43] R. A. Ghotli, A. R. Abdul Aziz, I. M. Atadashi, D. B. Hasan, P. S. Kong, and M. K. Aroua, "Selected physical properties of binary mixtures of crude glycerol and methanol at various temperatures," Journal of Industrial and Engineering Chemistry, vol. 21, pp. 1039-1043, 2015.

[44] S. Garg, A. M. Shariff, M. S. Shaikh, B. Lal, A. Aftab, and N. Faiqa, "Selected physical properties of aqueous potassium salt of l-phenylalanine as a solvent for $\mathrm{CO}_{2}$ capture," Chemical Engineering Research and Design, vol. 113, pp. 169-181, 2016. 


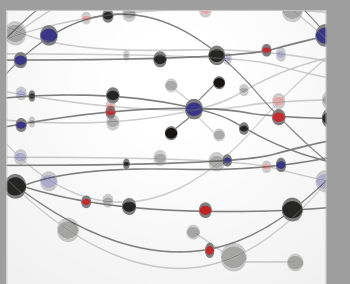

The Scientific World Journal
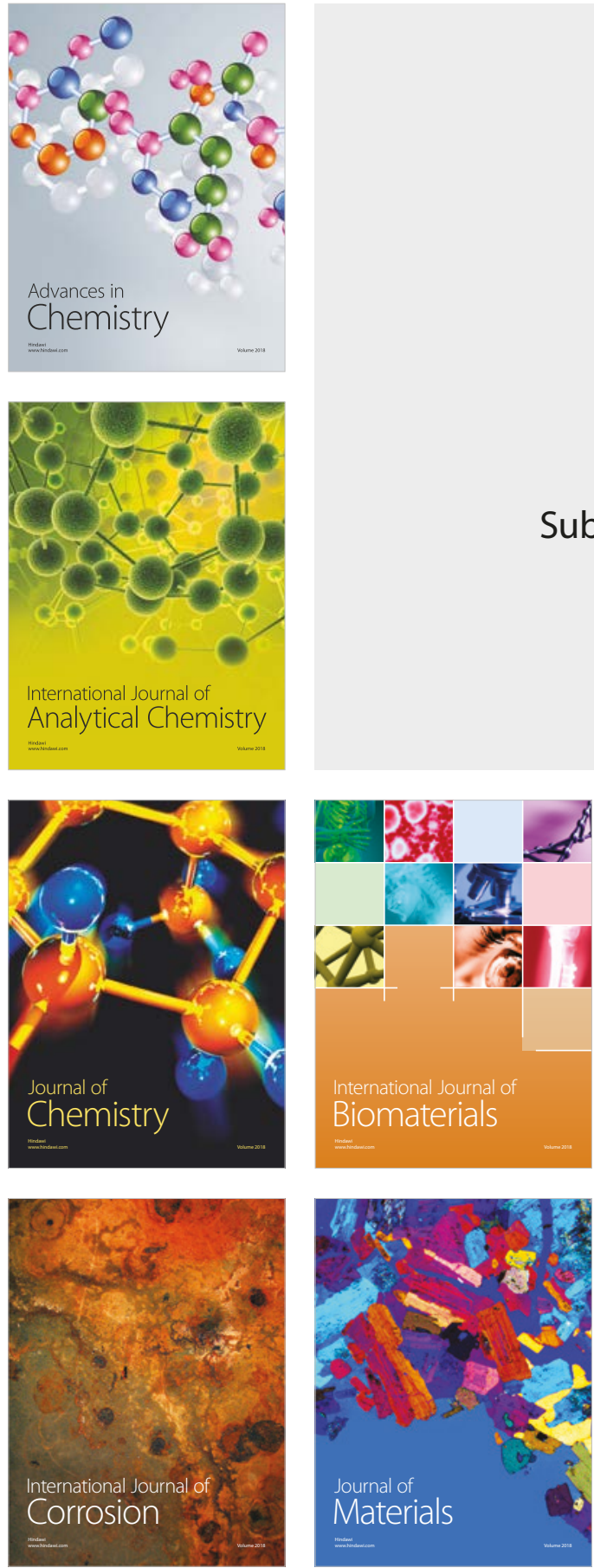

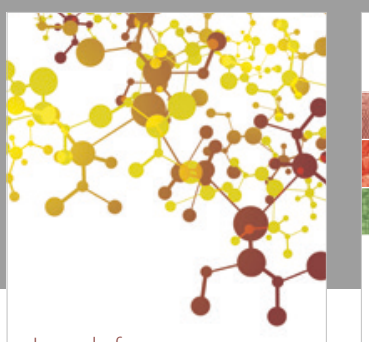

Journal of

Applied Chemistry
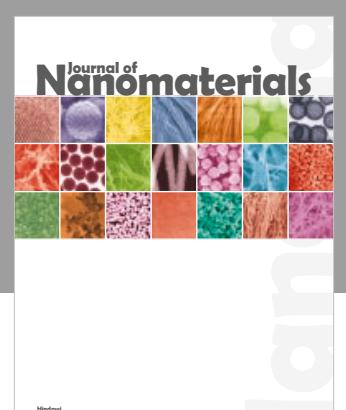

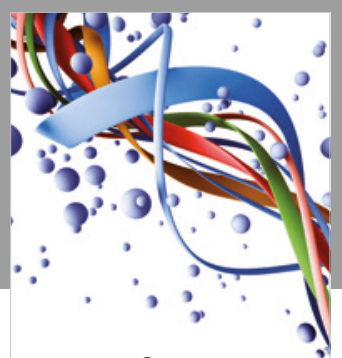

Scientifica

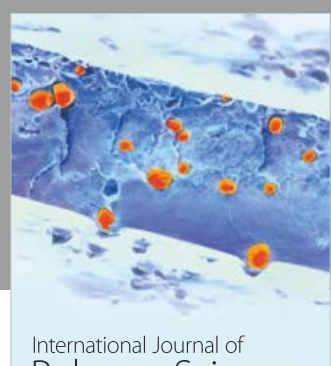

Polymer Science

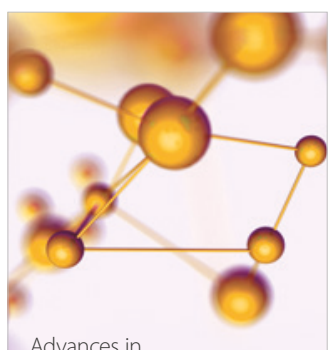

Physical Chemistry
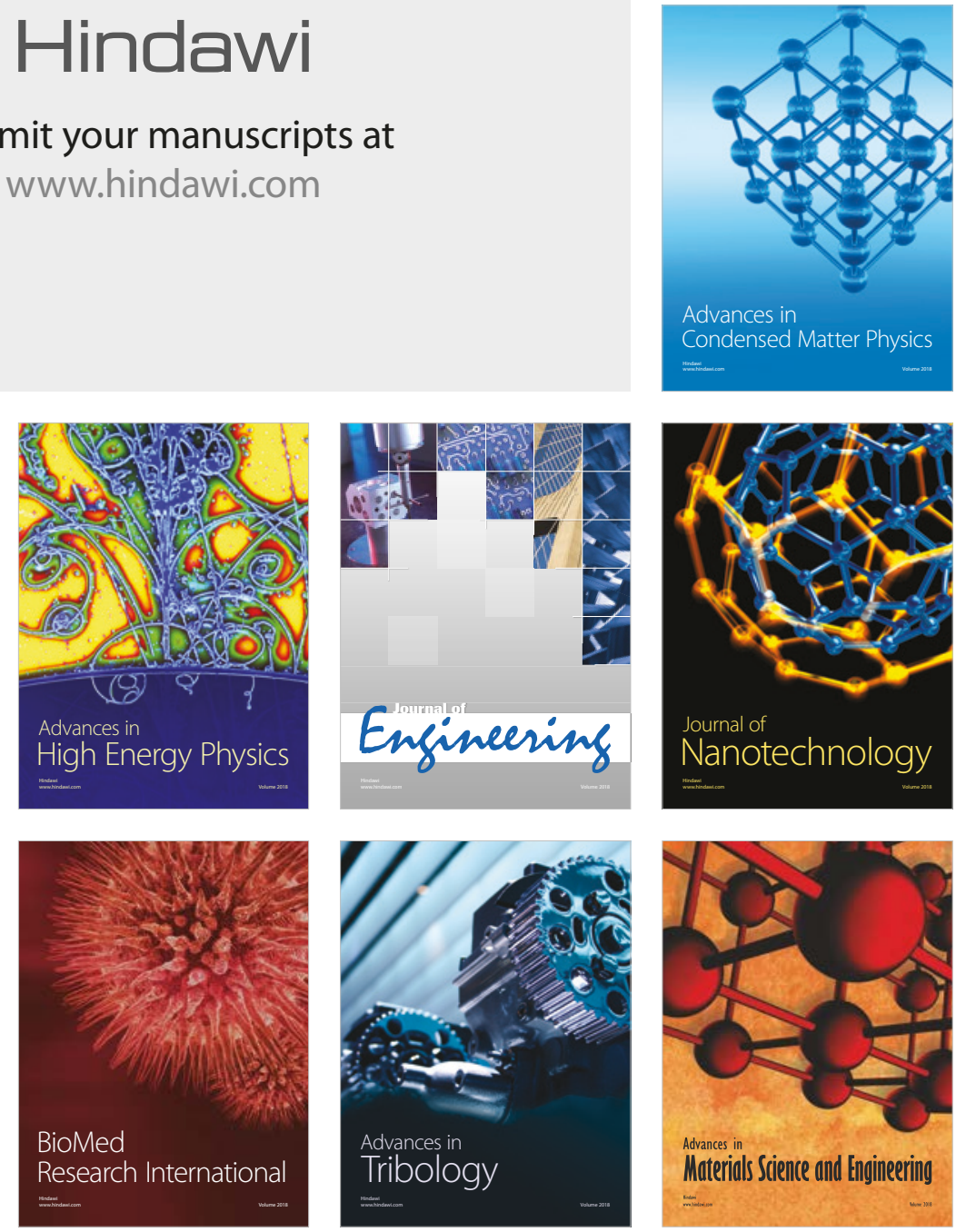